\title{
Flexibility Framework for Assessing Supplier Selection
}

\author{
Sara Robaty Shirzad and David Bell
}

\begin{abstract}
This paper focuses on the electronic procurement marketplace and the selection of suppliers, aided by flexibility factors. By judiciously employing decision flexibility and the associated dynamic control amongst autonomous EPM nodes, improvements are possible. Empirical data for this study was collected from pharmaceutical organization in UK using a discrete choice interview and analyzed using grounded theory techniques. The importance of flexibility was highlighted and prioritized with respect to supplier selection.
\end{abstract}

Index Terms-Electronic procurement marketplace (EPM), flexibility factors, supplier's selection.

\section{INTRODUCTION}

The changes of Web-based procurement marketplaces (Electronic procurement Marketplace- EPM) has altered different aspects of life; how businesses run with continuous changes, how organizations interact with their suppliers, and how people get use to Web evolution. Recently, rapid changes in business requirements and environments on the web-based marketplaces have put massive pressure on organizations to keep up and be more responsive and flexible. Moreover, the flow of failure in some EPM's and the success of others have led business managers to question the relative merits of each EPM. Flexibility in emerging organizational networks is also a concern [7] especially in a case of selecting suppliers. Organizations discover that it is essential to adopt EPM in order to achieve effectiveness and efficiency, with the majority of firms and suppliers being satisfied with its performance [19]. One such transformation is to consider of flexibility factors to remain competitive in a network environment. EPM's require to deliberate fundamental changes in technical, organizational, environmental and strategic in order to be responsive and flexible to the changes. From technical point of view, EPM's are faced with number of number of changes in hardware and software applications that need to be synchronized as Vizared (2001) stated. From an organizational perspective, flexibility can be applied at a number of internally or externally levels, for example to the variety of actual and potential procedures in order to increase the control capability of the management and improve the controllability of the organization and environment. Considerably, the ability or inability of management to predict new events happening in their organizational environments could be resulted in unbalancing between flow of orders and products [23]. Conceivably, ability in

Manuscript received August 30, 2012; revised September 30, 2012.

Sara Robaty Shirzad and David Bell are with Brunel University, Information Systems and Computing, London, UK (e-mail: Sara.robaty.shirzad@brunel.ac.uk, David.bell@brunel.ac.uk). identifying the changes in business strategy of the organization could be creating a new product and market combination, using market power to deter entry and control competitors, or engaging in political activities to counteract trade regulation [8]. From these flexibility perspectives, it could also be critical when applying new technologies (including platform or process changes to EPMs being utilized) and renewing products or services [1], [8].

Consequently, being able to identify and analyze flexibility challenges influencing supplier's selection in e-procurement based organization becomes vital in order to understand the complexity and effectiveness nature of considering this initiative. Hence the objective of this paper is to present a conceptual framework of the flexibility factors affecting supplier's selection in e-procurement based organization in order to illustrate clearly the nature of the phenomenon. Set of interviews has been conducted and the approach to the cases and interview content was through grounded theory method (GTM). Conceptual analysis presented here draws mostly on the literature of EPM and flexibility.

\section{LITERATURE REVIEW}

\section{A. Supplier's Selection in e-Procurement Marketplace}

With increasing corporate procurement and selling completed on-line every day, the number of EPM worldwide soared during the years preceding and beyond the millennium [15]. One of the reasons is that further technological development and advancement is occurring at a faster pace, resulting in new product innovations and improvements in manufacturing processes. The other reason that marketplace faced with is problem with selecting suppliers which are flexible with rapid and on-going changes in order to surpass the failure rate in the networked environment. A supplier becomes part of a well-managed and established EPM; it will have a lasting effect on the competitiveness of the entire system. The importance of supplier selection comes from the fact that "it commits resources while simultaneously impacting such activities as inventory management, production planning and control, cash flow requirements, and product quality" [17]. Selecting suppliers based on the factors that influenced the organization gives these opportunities to determine market price sensitivity and reduced search costs provided by internet technologies [12], [22]. In order to mitigate these affects a flexible system is expected to provide timely delivery when changing conditions occur, including changes in the short term demand [7]. Unsurprisingly, a major concern of procurement managers is responding and dealing with changes more effectively. Basically, it is how to choose the suppliers of the whole marketplace in a way that 
being responsive and flexible when the changes have been occurred. Indeed, by looking at the literature, it is clear that many authors over the last decade have focused on changes to EPM and selecting suppliers although few have considered how flexibility can be achieved. Thus, there is an on-going effort in the research community to develop appropriate framework to grasp preferences. Moreover, according to Pearson and Ellram (1995), an EPM environment entails a potentially large number of candidate suppliers as well as the participation of buyer organizations with divergent needs and characteristics, which in their turn correspond to the identification of different decision criteria for the selection of suppliers. Therefore, as Bartels (2005) stated, electronic marketplaces make an effort to provide effective flexible way for supplier assessment and selection to their participants in order to enhance their satisfaction and loyalty (e.g. Ariba, Emptoris, Perfect Commerce, etc.).Hence, in order for both the organizations and EPMs as a whole to remain agile and competitive, it is important to have a better understanding of flexibility factors in selecting suppliers in EPMs.

\section{B. Flexibility in Literature}

The term "flexible" is defined in Oxford dictionary as "ready and able to change so as to adapt to different circumstances". Upton (1995) describes flexibility as an ability to adapt to changing conditions that helps ensure continuity of the organization and rapidly respond to changes, coming from inside as well as outside the system. Fitzgerald (2002) considered flexibility as a necessary characteristic for organizations to deal with the threats and opportunities that are brought about by the increasing dynamics and complexity of environments. Examination of past studies present four general areas (technological, organizational, environmental and strategic) comprise the dominant forces influencing flexibility in organizations.

The flexibility types offered so far address flexibility partially, with primary focus on infrastructure and system. Furthermore, the issues of relationships and trade-offs between flexibility types and the strategic pathway for managing flexibility on supplier's selection in EPM have not been adequately addressed. The method presented in this paper is a synthesis of flexibility factors in the process of selecting suppliers, represented in section 3 .

\section{A SYNTHESIS OF FLEXIBILITY FACTORS INTO AN EPM FRAMEWORK}

In this section we synthesize the EPM and flexibility literature into a framework, providing a context from which the literature review can then be undertaken. Table 1 shows the need for flexibility summarized from the literature on EPM.

The literature provided a considerable number of factors that could be judged to influence the flexibility of EPM. The flexibility factors are synthesized in the framework and can be further explored according to levels of frequency of occurrence and influence on supplier selection. At the highest level, certain factors are determined by the organizational aspects in which the marketplace and companies operate. At the next level, certain factors are determined by strategic aspects in which the marketplace operates. A further two aspects are included - technical and environmental.

TABLE I: NEED FOR FLEXIBILITY ON EPM DOMAIN

\begin{tabular}{|l|l|}
$\begin{array}{l}\text { Flexibility is required to enable } \\
\text { rapid, effective, efficient and } \\
\text { non-disruptive }\end{array}$ & refences \\
\hline $\begin{array}{l}\text { Response to changing market } \\
\text { condition, regulations }\end{array}$ & {$[21]$} \\
\hline $\begin{array}{l}\text { Response to customers and suppliers } \\
\text { requirements }\end{array}$ & ([6], [13], [16]). \\
\hline Response to changes in technology & $([6],[13],[16])$. \\
\hline $\begin{array}{l}\text { Changes in business strategy } \\
\text { Changes in business models and } \\
\text { processes [14] }\end{array}$ & {$[4]$} \\
\hline $\begin{array}{l}\text { Changes in the level, location and type } \\
\text { of resources (e.g. data, storage, } \\
\text { applications, services, transactions, } \\
\text { bandwidth) }\end{array}$ & {$[21]$} \\
\hline $\begin{array}{l}\text { Changing in industrial relations and } \\
\text { coordination (agreements and } \\
\text { outsourcing arrangements) }\end{array}$ & $([10],[18])$ \\
\hline $\begin{array}{l}\text { Management of financial flow } \\
\text { Development or adoption and } \\
\text { deployment of products, services, } \\
\text { systems, infrastructure, logistics, } \\
\text { architecture, applications and data }\end{array}$ & $([3]-[5],[14])$ \\
\hline
\end{tabular}

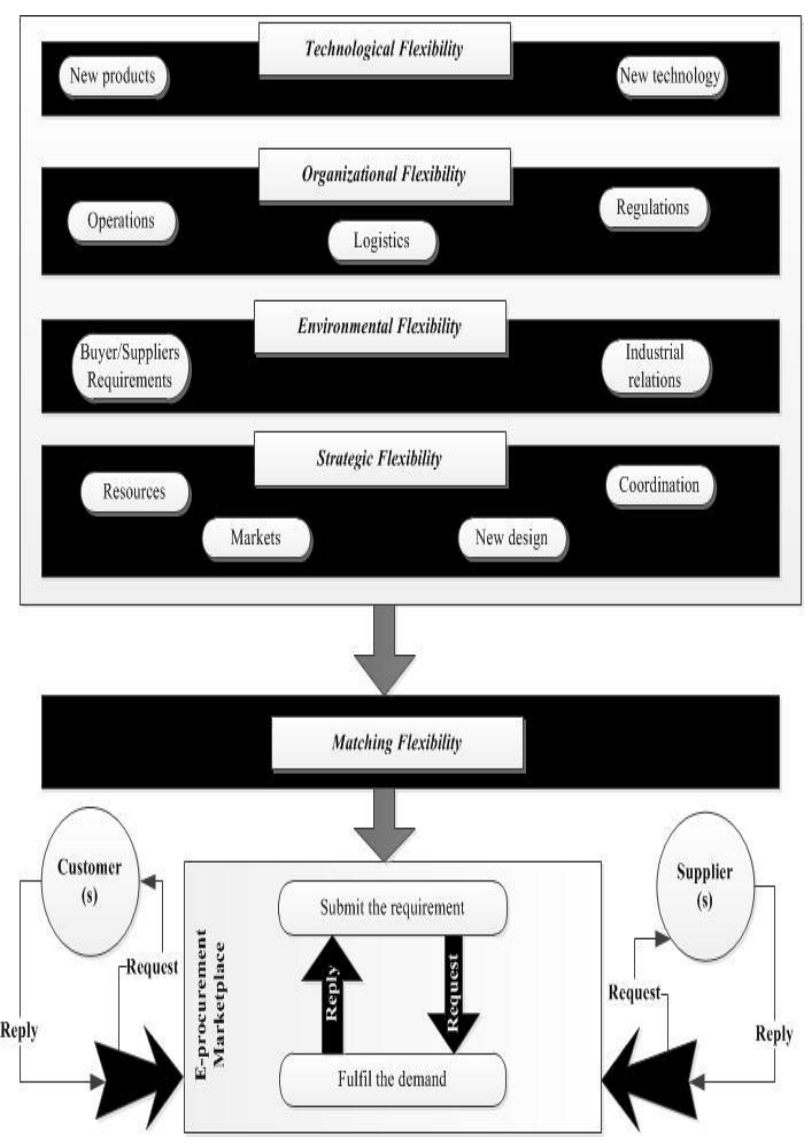

Fig. 1. A proposed framework of the flexibility of EPM 


\section{RESEARCH METHODOLOGY}

This research was carried out in three phases [11] namely: (a) research design, (b) data collection and (c) data analysis. As the current research attempts to validate the conceptual framework previously presented (illustrated in figure 1), therefore, based on the needs of the exploratory study, the authors decided that the research design would utilize an interpretive, qualitative case study approach to test the factors (as explained earlier). Interpretivism was adopted, as the aim of this paper is to find out the other flexibility factors involved in process of selection suppliers. Hence, the authors consider interpretivism as more appropriate for the research reported herein. The rationale for selecting a qualitative research methodology is that when an area of science is involved with human and organizational idiosyncrasies, qualitative research methods should be used [20]. Beside that events that form a phenomenon are conditioned by interacting variables, such as time and culture. Therefore quantitative research method is not suitable for this case as they are unable to take account of the differences between people and the objects of the natural sciences. In this research, the approach to data and theory has been based on abduction, where accounts of organisational phenomena are interpreted from narratives given by the actors themselves [2]. The role of the researcher in this style of research is to investigate organizational phenomena and to identify relationships and provide explanations. Typically, these type of organizational interactions need to be explored in detail with the appropriate participants and stakeholders, when examining a new or emerging phenomenon [24].In the context of this paper, the authors focused on a single case study (hereafter referred to as pharmaceutical organization (Pharma)-for confidentiality reasons the authors employ these coded name to refer to these entities). In this research, interviews constituted the main data source in the case organizations. Four participants from Pharma were interviewed using structured interviews. Structured interviews were based on an interview agenda whereby the interviewees replied to specific questions regarding e-procurement participation. Semi-structured interviews also took place but without the use of an interview agenda. Case studies can be conducted using a number of approaches, and as suggested by Hartley (1994), they may be seen as a research strategy which uses both quantitative and qualitative data. Interviews may produce problems of analysis, as the interview transcripts may be lengthy [22]. These data need to be subject to careful scrutiny and interpretation, which is largely achieved through the coding process. The approach to cases and interview content was through grounded theory method (GTM). GTM is the process of generating a theory from collected data [9]. The process is started with collecting data. After completing the relevant interviews, to write up a short case summary, to capture important points and initial insights; 2) once the interviews had been coded in detail, the case would be expanded around the findings from the coding process using Nvivo9; 3) these case reports were then refined or edited, in accordance with the focus of each paper; 4) relevant data would be extracted from the cases, according to the research questions or objectives of the specific article.

\section{Case Organization: Pharma}

Since the aim of this paper is to validate the conceptual framework (Figure 1) and the research presented herein is at an early stage, in this paper the authors only focused on finding the other influential factors (as discussed in Section 3 ). In doing so, a case study was undertaken with this section, and data is reporting from that. Selected case organization is situated in region of England and is responsible for providing services throughout various sectors such as: healthcare, social and environmental healthcare services, etc. As reported earlier, structured and semi-structured interviews were conducted in a case organization to investigate the decision-making process for supplier's selection. In achieving this, those factors considered to influence the decision-making process were identified from multiple perspectives. These perceptions were seen from those participants that were involved in the e-procurement process. The participants that were interviewed from Pharma included the: Head of procurement (HOP), Director Vendor management (DVM), Head of globally resourcing and procurement technology (RPT) and Procurement Operations Manager (POM).

\section{A. Flexible EPM and Supplier's Selection Problem}

The interview sessions highlighted that Pharma was faced with considerable pressures to cope with the selecting suppliers, while trying to meet requirements for processing systems, changes and most importantly focusing on implementing procurement in new platform to be more flexible. In addition, Pharma faced with the pressures on integrating SAP platform and challenges in terms of improving outsourcing and indirect suppliers. Pharma was also confronted with pressures to reduce the cost of implementations and forecasting the future changes in the organizations such as recently they have changes in management program internally to the company and externally. The interviewees at Pharma agreed that:

"..managing the changes in organization infrastructure was very much fragmented with respect to suppliers selection, different IT structure with no integration with supplier processing systems, lack of supplier's knowledge about the organizational infrastructure, transparency and visibility of procurement process prevailed...,"

Pharma's efforts to educate suppliers working with the new EPM platform have been hindered by organizational performance that has grown over the years. Pharma implemented various information systems and strategic planning to enhance their internal and external information with other suppliers. These systems did not solve all the problems as suppliers used a variety of operation systems and applications. These problems became an obstacle for Pharma as they had business goals for reducing the internal organization cost.

\section{B. Flexibility and Supplier's Selection Process}

The problem of spending time on educating suppliers led Pharma to take a decision to significantly advance on selecting suppliers by testing how flexible they are to develop an integrated suppliers selection. Head of procurement reported that: 
“... The reason for adopting flexibility factors is that according to the performance analysis from customer's feedbacks, we need to engage externally with more suppliers. Considering the fact that educating supplier is the most time consuming process, adopting the flexibility factors is reduction in the time spend on educating suppliers with the processing system, the cost of implementing IT structure for them and improvements in business process..."

Pharma was faced with the option of finding a method of migrating flexibility factors to supplier's selection in a new generation of systems (SAP). Later during the interview sessions, the interviewees were asked to highlight flexibility factors influencing on supplier's selection. Figure two presents the distribution of flexibility factors in Pharma. The factors gathered from interviewee's transcriptions. Accordingly the factors summarized based on four major categories previously founded on literature (TOES concerns) Analysis of the case data collected using the Grounded Theory techniques (discussed in section 4) resulted in 17 instances of different types of flexibility. These instances served as the basis for partitioning the concept of flexibility into four major categories containing 17 flexibility types.Thelevel of importance as presented in Table 2 (appendix) follows a scale similar totheoneusedby Miles and Huberman (1994) i.e. scale of lessimportant (๑), medium important (๑) and most important ( ).As highlighted in Table 2, the factors have varied findings and such preferences on the importance of factors by the interviewees are simply based on the interviewee's understanding and involvement during the changes in the organization.

\section{DISCUSSION}

Through the empirical findings presented earlier, the authors studied the area of electronic procurement marketplaces in terms of selecting suppliers by testing the flexibility factors. It is not the intention of this paper to offer prescriptive guidelines for flexibility in suppliers selection in Pharma's, but rather to describe case organization perspectives that allow others to relate their experiences to those reported. Hence, this paper offers a broader understanding of the phenomenon of flexibility factors in assessing supplier's selection in Pharma as an example of procurement organization. Therefore, what we learnt from the case study conducted is a result of the description provided and do not seek to be prescriptive. It is clear from responses provided by the interviewees that most of the flexibility factors have influenced supplier's selection in Pharma. As reported earlier, this paper is a conceptual paper and the authors intended to validate their conceptual framework and get feedback from the case organization regarding the acceptability of the conceptual framework presented. In doing so, the results, in the form of importance of factors (Table II), illustrate that the conceptual framework is accepted within the case organization. Moreover, the data collected from the case organization was confirmed to be of relatively similar significance with marginal differencesthus increasing the validity of the conceptual framework. The importance of factors presented in this paper provides a direction for consideration of the evaluation of flexibility in the organization with respect to supplier's selection in EPM. Moreover, the case study of Pharma provides an illustrative reference for such evaluation. Therefore, the analysis presented in this paper would be beneficial for evaluation supplier's selection in the organizations while also investigating its flexibility factors.

\section{CONCLUSION}

Literature and empirical research are combined to explore the importance of EPM flexibility factors when selecting suppliers. A number of interviews were undertaken at Pharma in the U.K and transcripts were analyzed using grounded theory techniques. Supplier selection flexibility factors are prioritized in order to provide guidelines for constructing effective and resilient market structures.

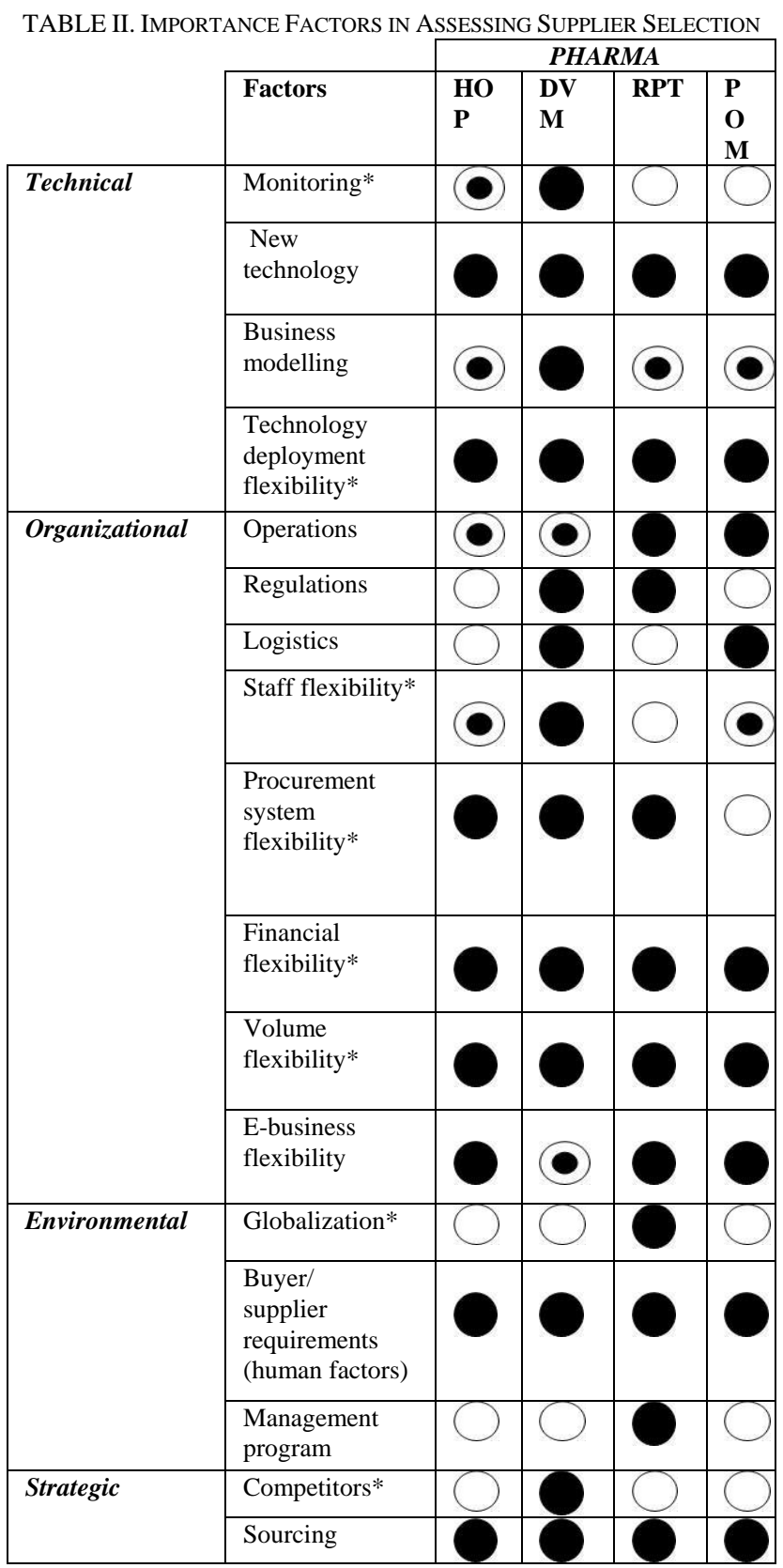




\section{REFERENCES}

[1] D. A. Aaker and B. Mascarenhas, "The need for strategic flexibility," Journal of Business Strategy, vol. 5, no. 2, pp. 74-82, 1984

[2] P. Blaikie, "Changing environments or changing views? A political ecology for developing countries," Geography, pp. 203-214, 1995

[3] A. C. Boynton, "Achieving dynamic stability through information technology," The New Management Reader, pp. 181, 1996

[4] T. A. Byrd and D. E. Turner, "Measuring the flexibility of information technology infrastructure: Exploratory analysis of a construct," Journal of Management Information Systems, vol. 17, no. 1, pp. 167-208, 2000

[5] B. Evans, "The need for agility," InformationWeek August 26, vol. 903, pp. 80, 2002.

[6] G. Fitzgerald, "Achieving flexible information systems: the case for improved analysis," Journal of Information Technology, vol. 5, no. 1, pp. 5-11, 1990

[7] G. Fitzgerald, M. Barad, A. Papazafeiropoulou, and G. Alaa, "A framework for analyzing flexibility of generic objects," International Journal of Production Economics, vol. 122, no. 1, pp. 329-339, 2009

[8] G. Fitzgerald and F. A. Siddiqui, "Business process reengineering and flexibility: a case for unification," International Journal of Flexible Manufacturing Systems, vol. 14, no. 1, pp. 73-86, 2002

[9] B. G. Glaser and A. L. Strauss (1967) the discovery of grounded theory: Strategies for qualitative research, Aldine Transaction.

[10] A. Harris, L. C. Giunipero, and G. T. M. Hult, "Impact of organizational and contract flexibility on outsourcing contracts," Industrial Marketing Management, vol. 27, no. 5, pp. 373-384, 1998

[11] A. D. Jankowicz, Business research projects, Cengage Learning EMEA, 2005

[12] S. Jap, "Going, going, gone," Harvard business review, vol. 78, no. 6, pp. 30,2000

[13] F. Land, "The information systems domain," Information systems research: issues, methods and practical guidelines, pp. 6-13, 1992

[14] L. Legorreta, K. Nelson, and H. J. Nelson, "Framework for Measuring E-Business Architecture Flexibility," 2001

[15] J. Li and L. Li, "On the critical success factors for B2B e-marketplace," Proceedings of the 7th international conference on Electronic commerce ACM, pp. 119, 2005

[16] G. Longworth, Designing systems for change, Wiley-Blackwell, 1985

[17] R. Narasimhan, "An analytical approach to supplier selection, journal of Purchasing and Materials Management," vol. 19, pp. 27-32, 1983

[18] K. M. Nelson, H. J. Nelson, and M. Ghods, "Technology flexibility: conceptualization, validation, and measurement," System Sciences,
1997, Proceedings of the Thirtieth Hawaii International Conference on IEEE, pp. 76, 1997

[19] M. Rask and H. Kragh, "Motives for e-marketplace Participation Differences and Similarities between Buyers and Suppliers," Electronic Markets, vol. 14, no. 4, pp. 270-283, 2004

[20] D. Remenyi and B. Williams, "The nature of research: qualitative or quantitative, narrative or paradigmatic? "Information Systems Journal, vol. 6 , no. 2, pp. 131-146, 1996

[21] A. K. Sethi and S. P. Sethi, "Flexibility in manufacturing: a survey," International Journal of Flexible Manufacturing Systems, vol. 2, no. 4 pp. 289-328, 1990

[22] A. Smart, "Exploring the business case for e-procurement," International Journal of Physical Distribution \& Logistics Management, vol. 40, 2010

[23] R. J. Vokurka and S. W. O'Leary-Kelly, "A review of empirical research on manufacturing flexibility," Journal of Operations Management, vol. 18, no. 4, pp. 485-501, 2000

[24] R. K. Yin, "Case study research," Design and methods, vol. 5, 1994

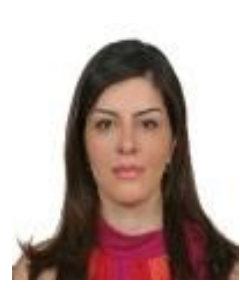

Computing.

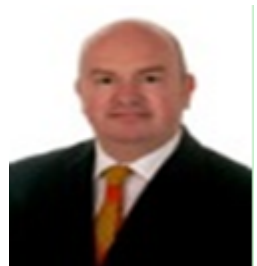

Sara Robaty Shirzad is a $\mathrm{PhD}$ researcher in the Department of Information Systems and Computing at Brunel University (UK). Her current research focuses on influencing of flexibility factors in the process of selecting suppliers in EPM-based organization. Sara is involved in teaching undergraduate and postgraduate courses within the Department of Information Systems and business setting, Dr. Bell is investigating the use of semantic technologies to facilitate software re-use and matching in business and pervasive environments. Dr. Bell spent 15 years working in the IT industry, primarily within Investment Banking, latterly as Technology Director. He has managed a number of global software development projects with over 100 staff. 